\title{
E SE VAZAR, DERRAMAR E EXPLODIR? O TRANSPORTE RODOVIÁRIO DE PRODUTOS PERIGOSOS NA BAHIA, BRASIL
}

\section{WHAT IF THEY LEAK, SPILL AND EXPLODE? THE TRANSPORTATION OF HAZARDOUS MATERIALS ON HIGHWAYS IN BAHIA, BRAZIL}

Lívia Maria da Silva Gonçalves

Mestre em Saúde, Ambiente e Trabalho, Universidade Federal da Bahia. (liviajeje@yahoo.com.br)

Luiz Roberto Santos Moraes

PhD em Saúde Ambiental, University of London - UK. Universidade Federal da Bahia / Departamento de Engenharia Ambiental. (moraes@ufba.br)

\section{Cláudia de Oliveira D'Arede}

Mestre em Saúde, Ambiente e Trabalho, Universidade Federal da Bahia. Universidade Federal da Bahia / Departamento de Medicina Preventiva e Social. (claudiadared@gmail.com)

\section{Resumo}

A Bahia é um dos principais corredores de transporte rodoviário de produtos perigosos do Brasil e do Mercosul, bem como de seus eventos adversos no trânsito. Este artigo visa a delinear um diagnóstico do transporte rodoviário de produtos perigosos na Bahia, levantando seu panorama geral e as vulnerabilidades e avanços vigentes, utilizando revisão bibliográfica, análise documental e entrevistas com alguns gestores envolvidos na temática. Os resultados indicam que há vulnerabilidades associadas às seguranças viária, química, institucional, política e populacional. A Região Metropolitana de Salvador é a concentradora do fluxo e dos eventos adversos com estes materiais, sendo os combustíveis líquidos, gases e corrosivos os produtos perigosos que se destacam e com danos e prejuízos que extrapolam o limite espaço-temporal. 0 problema é de ordem estrutural no Estado, o que exige um olhar diferenciado para que o torne uma de suas prioridades, embasado nos pressupostos de um planejamento integrado e participativo, refletindo na gestão e gerenciamento desse risco tecnológico ambiental na Bahia.

Palavras-chave: rodovias; transporte de produtos perigosos; risco.

\section{Abstract}

The highways in Bahia have some of the heaviest traffic of dangerous cargo in Brazil and Mercosul as well as adverse traffic accidents. This descriptive article aims to outline the diagnosis of Road Transport of Hazardous Materials in Bahia, showing the general overview of current vulnerabilities and advances, based on: bibliographical review, documentary analysis and interviews with managers involved in the scenario. The results indicate that there are vulnerabilities regarding road, chemical, institutional, political and population safety and security. The Metropolitan Area of Salvador has the highest concentration of dangerous goods such as liquid fuels, corrosive materials, gases in circulation as well as the majority of accidents of this type with damages and losses that go beyond the limit. The problem is of a structural nature within the State that requires special considerations to make it one of its priorities, based on the assumptions of integrated and participative planning, reflected in the management of this environmental and technological risk in Bahia.

Keywords: highways; hazardous materials transportation; risk.

\section{INTRODUÇÃO}

O Brasil ocupa a sexta posição mundial de produção de produtos e insumos químicos e petroquímicos, demandando uma movimentação intensa de produtos perigosos pelo modo preferencial de transporte do País, o rodoviário. A Confederação Nacional do Transporte (CNT) indica que $61,1 \%$ de toda carga movimentada no País é realizada por esta modalidade de transporte, com aproximadamente $43 \%$ associados aos produtos ou materiais perigosos. Daí, então, o número expressivo de eventos de trânsito com tais materiais, devido às condições a que está exposto, podendo ocorrer por tombamentos, colisões, vazamentos, dentre 
outras causas, e, por consequência, acontecer incêndios, explosões, contaminação de corpos d'água, solos, atingindo a fauna e a flora, patrimônios naturais e construídos e, principalmente, perdas humanas (IBAMA, 2015; CNT, 2016; GONÇALVES et al., 2017).

A Bahia se encontra entre os sete estados do Brasil que se destaca em eventos adversos com produtos perigosos, dentre os quais estão os associados ao transporte rodoviário, devido aos grandes empreendimentos industriais existentes em seu território, como: o maior polo industrial do Hemisfério Sul, o Polo Industrial de Camaçari; a segunda maior refinaria de petróleo do País, a Refinaria Landulpho Alves; o Porto de Aratu, dentre outros. A exigência de um fluxo intenso desses materiais por suas rodovias propicia às populações lindeiras, aos trabalhadores que lidam diretamente com esses materiais e ao ambiente uma exposição contínua aos perigos e riscos das suas propriedades intrínsecas, bem como aos passivos socioambientais, caso ocorra eventos de trânsito cuja abrangência ultrapasse os limites espaço-temporais, com sérios danos e prejuízos para o Estado e a sociedade (BELTRAMI; FREITAS; MACHADO, 2012; IBAMA, 2015; GONÇALVES, 2017).

A Organização das Nações Unidas (ONU) conceitua produtos perigosos como substâncias naturais ou artificiais que apresentam propriedades físico-químicas como toxicidade, inflamabilidade, corrosão, dentre outras, que possam causar danos e prejuízos às populações, ambiente natural e construído. Esses materiais estão agrupados em nove classes de risco para o campo do transporte: gases, líquidos inflamáveis, sólidos inflamáveis, substâncias oxidantes e peróxidos orgânicos, substâncias tóxicas infectantes, radioativos, substâncias corrosivas e substâncias e artigos diversos. Há, ainda, outros produtos perigosos que transitam nas rodovias, mas, por não apresentarem estudos toxicológicos e ecotoxicológicos de suas propriedades, não estão classificados em nenhuma daquelas classes, tornando-se mais um risco potencial móvel incorporado aos já existentes.

Este artigo tem como objetivo delinear um diagnóstico do transporte rodoviário de produtos perigosos (TRPP) na Bahia, identificando as vulnerabilidades e avanços sobre a temática em um dos estados de relevância econômica para o País. Utilizou-se revisão bibliográfica, análise documental e informações obtidas em alguns órgãos quanto ao transporte em estudo. Assim, é esperado que se possa contribuir com as práticas da gestão e gerenciamento de risco em TRPP no Brasil, tendo como um de seus instrumentos o planejamento ambiental integrado e participativo, já que a Política Ambiental do Ministério dos Transportes tem o ambiente como um dos seus pressupostos aliado aos econômicos, sociais e técnicos.

\section{METODOLOGIA}

O presente artigo é de natureza exploratória e descritiva e de abordagem qualitativa. Foram realizadas revisão bibliográfica e análise documental das condições vigentes do transporte rodoviário de produtos perigosos (TRPP) na Bahia. A base de dados do Portal Capes norteou a revisão de conceitos e dos cenários internacional e nacional desse modal de transporte. Os documentos utilizados para elaboração deste artigo foram os estudos e relatórios existentes das condições de TRPP no estado da Bahia e que abrangem o período dos anos 80 até o ano de 2018, oriundos dos campos da administração direta e indireta e da gestão privada (concessionária e Polo Industrial de Aratu). Algumas informações de instituições públicas e privadas que não puderam ser auferidas diretamente por meio de entrevistas e por documentos que poderiam ser liberados por aquelas devido à inexequibilidade de tempo ou, até mesmo, por indisponibilidade de dados foram parcialmente supridas por visitas aos seus sites ou por intermédio de outros atores sociais que poderiam facultá-las.

Dados empíricos logrados por meio de entrevistas semiestruturadas com gestores do campo do TRPP, associações dos trabalhadores (condutores de produtos perigosos e do campo do Transporte estadual) e população lindeira existente em uma das principais rodovias da Região Metropolitana de Salvador de expressivo fluxo de produtos perigosos foram também contemplados nesse artigo, integrando a composição do diagnóstico do TRPP no estado da Bahia.

Quando necessário, alguns dados envolvendo resultados de fiscalização das condições de TRPP em rodovias baianas, concentrados diretamente na Região Metropolitana de Salvador (RMS), desenvolvidos pela Agência Nacional de Transporte Terrestre (ANTT) e disponibilizados pelos órgãos públicos de trânsito e segurança, foram tratados com os 
pressupostos da estatística descritiva e com 0 uso do programa Excel versão 2016. As análises dos dados foram realizadas segundo a literatura $e$ autores críticos do campo em estudo e da observação in loco, por meio do diário de campo que, também, foi uma das fontes de dados de complementação do diagnóstico proposto e entendimento de determinadas questões.

As entrevistas e obtenção de certos dados ocorreram por meio de Termo de Consentimento Livre e Esclarecido (TCLE) e Termo de Compromisso de Utilização de Dados (TCUD) sob $n^{\circ}$ CAAE 63252116.6.0000.557, em consonância com o projeto aprovado no Conselho de Ética em Pesquisa (CEP) da Faculdade de Medicina da Bahia da Universidade Federal da Bahia.

A utilização de alguns conceitos neste trabalho é feita levando em consideração perspectivas críticas dos campos da Saúde, do Trânsito e do Ambiente. Assim, os acidentes de trânsito neste artigo serão denominados de eventos de trânsito, adotando-se o conceito de Honorato (MOREIRA, 2015). Tal escolha foi feita observando os princípios da Teoria da Responsabilidade Objetiva do Estado Brasileiro, oriunda do Campo do Direito Administrativo e validada pela lei maior de trânsito do País (Código de Trânsito Brasileiro), em relação ao dever da segurança viária para os cidadãos e em assumir todas as consequências de uma gestão e gerenciamento em TRPP, seja por ação ou omissão, e que refletirão diretamente nas esferas da saúde, do ambiente, socioeconômica e cultural.

No campo da gestão e gerenciamento de risco tecnológico ambiental em TRPP, há um uso internacional de duas expressões da língua inglesa: dangerous goods e hazardous materials (hazmat). A primeira refere-se às consequências físicas ou químicas que estes produtos podem provocar. Já a segunda se relaciona aos impactos à saúde; os materiais são conhecidos por QBRN (químicos, biológicos, radiológicos e nucleares). Por entender que a segunda é mais abrangente e por ser um descritor em Ciências da Saúde, foi esta a empregada neste artigo.

O conceito de risco potencial aqui adotado baseia-se no Princípio da Precaução, conforme é apregoado como o 15ำ Princípio da Declaração do Rio/92 sobre Meio Ambiente e Desenvolvimento Sustentável. Tal princípio foi estabelecido na Conferência no Rio de Janeiro, em 1992, como "a garantia contra os riscos potenciais que, de acordo com o estado atual do conhecimento, não podem ser ainda identificados" e que, para tanto, incentiva a governança de risco e seus atributos, como gestão transparente, democrática e participação integrada. Acordado pelo Brasil, esse princípio tornou-se um dos componentes das políticas públicas e ações dos atores sociais envolvidos na questão e vem sendo fortalecido ante o TRPP ser uma atividade de risco incerto, complexo, globalizado, naturalizado e invisibilizado. Desse modo, entende-se risco potencial como uma possibilidade de ocorrência de um evento adverso, conforme Navarro (2009).

O entendimento de segurança química utilizado é o mencionado por Freitas et al. (2002), que se refere ao conjunto de estratégias para o controle e a prevenção dos efeitos adversos de substâncias químicas para o ser humano e o meio ambiente. Ressalta-se que os produtos perigosos abrangem materiais de naturezas biológica, química, radioativa e nuclear, em conformidade com a sua classificação internacional para transporte, o que leva a uma consideração sobre o termo restritivo à química, mas que não é o presente objetivo. Aqui será entendido como uma parte da política internacional de segurança para o homem e o ambiente, ao lidar com estes produtos desde sua produção até a disposição final ambientalmente adequada e que atinge os perigos das propriedades intrínsecas a tais materiais.

Um conceito primordial para a questão tratada é o de Sánchez (2008) sobre o risco tecnológico ou, também como é conhecido, risco tecnológico ambiental ou, ainda, risco ambiental tecnológico, que o define como aquele de origem antropogênica, podendo ser de natureza industrial, biológica e outros, o que atende completamente o estudo sobre TRPP.

\section{RESULTADOS E DISCUSSÃO}

\section{Panorama Geral do TRPP na Bahia}

O transporte rodoviário de produtos perigosos (TRPP) é compreendido como a circulação em rodovias e em vias públicas de produtos considerados perigosos, ou seja, materiais e/ou substâncias que causam risco à saúde do homem e ao ambiente, conforme a Resolução no 5581/2017 da Agência Nacional de Transportes Terrestres (BRASIL, 2017), autarquia federal, vinculada ao Ministério dos Transportes, 
que tem como funções a regulação e a fiscalização do transporte terrestre, abrangendo, assim o TRPP.

O que diferencia o TRPP de outras modalidades de transporte de cargas é a tipologia de materiais com qual ele trabalha e que, em condições inadequadas, pode gerar efeitos de amplitude diversa, necessitando de uma gestão e gerenciamento apropriados à sua natureza complexa, pois, como consideram Porto e Finamore (2012), esse é um campo onde há um domínio de incertezas técnicas, metodológicas e epistemológicas. O risco ambiental tecnológico associado ao TRPP engloba as etapas dos processos produtivos desde a síntese dos materiais até a disposição de seus resíduos, contudo, é na etapa de transporte que se apresenta o maior número de eventos adversos, pois o risco potencial envolvido é eminentemente móvel e, sob determinados cenários, pode causar danos e prejuízos irreversíveis. As rodovias são o principal cenário de riscos no transporte de produtos perigosos.

Conforme Araújo (2013) e Gonçalves (2017), as ferramentas utilizadas para uma gestão, gerenciamento e controle eficazes e efetivos dos riscos envolvendo o TRPP são o mapeamento de riscos, que consiste em levantar as ameaças, vulnerabilidades, avanços e capacidades neste campo, e o uso de metodologias de avaliação de riscos, em que possam ser formuladas políticas públicas e tomadas de decisão mais assertivas. Segundo Freitas et al. (2013), não há levantamento de ameaças naturais e nem tecnológicas no estado da Bahia, o que expõe sua população a cenários de riscos que podem resultar em desastres. Já as Instituições de Segurança, como a Proteção e Defesa Civil Estadual (SUDEC), e de emergência em Saúde, como o Serviço de Atendimento Móvel de Urgência do Estado da Bahia (SAMU-BA), informaram, por meio de entrevistas, a urgência de fortalecer a intersetorialidade para elaboração de mapeamento de riscos e vulnerabilidades e plano de contingência, hoje inexistentes. Em se tratando do TRPP, é premente a necessidade de visibilizar a questão devido às vulnerabilidades neste campo (SUDEC, 2016; SAMU-BA, 2017).

As instituições públicas interpeladas (esferas federais, estaduais e municipais) afirmaram que não usam metodologias de avaliação de riscos ao lidar com a temática em estudo, contrariando o Plano Nacional de Prevenção, Preparação e Resposta Rápida a Emergências Ambientais com
Produtos Químicos Perigosos (P2R2) e a Resolução CEPRAM no 4.578/2017 (BRASIL, 2007; BAHIA, 2017; GONÇALVES, 2017) que trata do gerenciamento de riscos acidentais para substâncias perigosas na Bahia. As instituições em que foram aplicadas as entrevistas são as seguintes: ANTT-BA (Agência Nacional de Transportes Terrestres na Bahia), SEINFRABA/SIT (Secretaria de infraestrutura do Estado da Bahia/Superintendência de Infraestrutura de Transportes da Bahia), DNIT-BA (Departamento Nacional de Infraestrutura de Transportes na Bahia), DETRAN-BA (Departamento Estadual de Trânsito da Bahia), TRANSALVADOR (Superintendência de Trânsito de Salvador), PRFBA (Polícia Rodoviária Federal na Bahia), PREBA (Polícia Rodoviária Estadual), CBM-BA (Corpo de Bombeiros Militar da Bahia), COI (Centro de Operações e Inteligência da Bahia), DIVISA/COVIAM (Diretoria de Vigilância Sanitária e Saúde Ambiental/Coordenação de Vigilância Ambiental), SAMU-BA (Serviço de Atendimento Móvel de Urgência da Bahia), SUDEC (Superintendência Estadual de Proteção e Defesa Civil da Bahia), IBAMA-BA (Instituto Brasileiro do Meio Ambiente e Recursos Naturais Renováveis na Bahia), AGERBA (Agência Estadual de Regulação de Serviços Públicos de Energia, Transportes e Comunicações da Bahia), SINDICARGAS (Sindicato dos Trabalhadores em Transportes Rodoviários de Cargas do Estado da Bahia), SASDERBA (Associação Assistencial dos Servidores do Derba) e uma das populações lindeiras (quilombola) no entorno da rodovia BA524, na RMS.

As instituições supracitadas, por meio de entrevistas e alguns planos de gerenciamento de riscos associados ao TRPP, disponibilizados por algumas instituições privadas e outros obtidos em sites, mostraram a valorização da natureza objetiva do risco, o que privilegia as evidências técnico-científicas em detrimento também do seu caráter subjetivo, refletindo na frágil participação e controle social na temática.

A questão ambiental de TRPP está intrinsecamente ligada às exigências de um transporte seguro e à gestão e gerenciamento eficientes e efetivos, portanto, variáveis, como condições dos veículos, das vias, características e condições do meio ambiente sob a influência direta e indireta dos transportes, os usuários, dentre outras, são avaliadas neste campo (ARAÚJO, 2007; GONÇALVES et al., 2017).

As entrevistas realizadas e as análises de 
relatórios facultados pelas instituições públicas que possuem bancos de dados específicos para eventos de trânsito com TRPP, como PRF-BA, PRE-BA e SEINFRA/SIT, e pela Secretaria de Saúde do Estado da Bahia (DIVISA/COVIAM) indicaram a presença de subnotificação nesses registros e ausência de banco de dados integrados. Tais vulnerabilidades, aliadas às arduidades na obtenção desse tipo de dado nos órgãos ambientais, em concessionárias rodoviárias e no DNIT-BA, devido à frágil intersetorialidade atual com a PRF-BA, e, assim, o não envio deste àquela, bem como os bancos de dados associados ao licenciamento/autorização corroboram para as seguintes dificuldades: a) delineamento mais completo do cenário desse transporte no estado; b) uso de metodologias de avaliação de risco que exige histórico e frequências de eventos de trânsito; c) controle mais rigoroso; d) mais investimentos na gestão e gerenciamento de TRPP; e e) identificação da possibilidade de existência de TRPP ilegal no estado da Bahia, apontando essa fragilidade político-institucional.

Não há plano viário para o estado da Bahia e nem foi implementado o seu plano de contingência para cargas perigosas, segundo informações da Superintendência de Infraestrutura de Transporte da Bahia (SIT, 2017a), em entrevista, e um estudo disponibilizado sobre a situação do TRPP na Bahia. Tal cenário nos leva à reflexão sobre a importância da questão para o estado, ou do pensamento de que o setor industrial dará conta do problema com o uso de tecnologias, mesmo com estas em constante evolução e se defrontando com as incertezas tecnológicas advindas dos riscos complexos deste campo, ou, simplesmente, mostrando que os interesses econômicos suplantam a segurança da população e do ambiente.

O TRPP na Bahia ocorre via granel e fracionado (SIT, 2017b) e os tipos de veículos que se destacam para este tipo de transporte são os bitrens e rodotrens, respectivamente. Assim, a capacidade de volumes transportados deles variam de $38.000 \mathrm{~L}$ a $57.000 \mathrm{~L}$ e $48.000 \mathrm{~L}$ a $74.000 \mathrm{~L}$, respectivamente, de produtos perigosos. Isto significa que a população baiana, diariamente, se encontra exposta não somente a um material em trânsito, mas também à possibilidade, em um mesmo veículo, de coexistir, em tanques distintos, produtos diferentes e com propriedades semelhantes. Assim, há probabilidade de riscos potenciais que podem ser independentes, aditivos, potencializadores, antagônicos e/ou sinérgicos, os quais, submetidos a condições inapropriadas, favorecem a ocorrência de eventos de trânsito com consequências socioambientais e econômicas de abrangência e amplitudes variadas e de efeitos agudos e crônicos.

O DETRAN-BA (2017) informou que a idade da frota dos veículos ultrapassa o exigido por lei, assinalando mais um risco potencial em TRPP encontrado na Bahia e mais uma vulnerabilidade político-institucional que refletirá na vulnerabilidade populacional, em que uma das condições exigidas para este tipo de transporte não é atendida. Há de se perguntar sobre a falta de ingerência pública na inconformidade encontrada.

A Região Metropolitana de Salvador (RMS) concentra o fluxo pesado do TRPP estadual, bem como a maior parte da estrutura emergencial em caso de eventos adversos devido aos grandes empreendimentos industriais localizados neste território, e o maior número de instituições privadas atuantes na gestão, gerenciamento e controle de riscos e desastres em TRPP do estado da Bahia e de seus eventos de trânsito. Em tais eventos, os materiais perigosos de destaque são os combustíveis líquidos, gases e corrosivos, concordando com a literatura internacional (GONÇALVES, 2017).

No que tange aos eventos de trânsito com produtos perigosos no período de 2010 a 2014, foram notificados 159 acidentes com 11 óbitos nas rodovias federais baianas e 19 nas rodovias estaduais, com custos aproximados de $R \$ 14$ milhões, não existindo estruturas hospitalar, técnica e tecnológica para grandes eventos de trânsito com TRPP (PRF-BA, 2015; INEMA,2015; GONÇALVES; D'AREDE; MORAES, 2018).

Os estudos de riscos, de uma maneira geral, são escassos na Bahia e mais ainda em termos de riscos tecnológicos ambientais para TRPP (GONÇALVES, 2017).

\section{Gestão, Gerenciamento e Controle do TRPP}

A atividade de TRPP pertence a um campo que envolve riscos de natureza complexa e, como tal, demanda diversos atores sociais, sejam das esferas públicas (federal, estadual e municipal, esta última dependendo da gestão local e respeitando as devidas competências), sejam das privadas. 
Por meio de análise de documentos cedidos pelas instituições visitadas e da legislação específica, bem como de entrevistas realizadas com os atores sociais já supracitados, verificou-se que a percepção e participação das populações lindeiras e de centros urbanos expostas a uma grande circulação do TRPP não estão inseridas no processo do controle. Os campos que se destacam historicamente na gestão, gerenciamento e controle desta modalidade de transporte, por conta de suas atuações serem mais intensas e conhecidas pela sociedade nas etapas de fiscalização e emergencial, são os órgãos públicos associados aos Transportes, Trânsito, Segurança e Proteção e Defesa Civil, Ambiente, Saúde e Educação e as instituições privadas. Sobre o campo da Educação, salientase que as ações que mais se destacam são as relacionadas à formação do condutor em TRPP, realizadas pelo Departamento Estadual de Trânsito da Bahia (DETRAN-BA), por alguns centros de formação de condutores credenciados por este e pelo Serviço Social do Transporte/Serviço Nacional de Aprendizagem do Transporte (SEST/SENAT), no qual também ocorrem cursos de atualização desta classe de condutores.

Há outras instituições públicas cujas atribuições são despercebidas e parecem ser indiretas ao TRPP, no entanto, são imprescindíveis ao desenvolvimento da atividade nos campos da logística de transportes e que refletem diretamente nos setores econômico, tecnológico e científico, como, por exemplo, o Instituto Baiano de Metrologia e Qualidade (IBAMETRO) e a Secretaria da Fazenda do Estado da Bahia (SEFAZ-BA), sendo, assim, alocadas no campo das instituições denominadas de estruturantes. Os autores desta pesquisa indicam que o controle em TRPP abrange as etapas de regulação, licenciamento/autorização, fiscalização, educação, emergencial e monitorização.

Por meio das visitas às instituições $e$ apreciação da legislação e de documentos pertinentes, os autores chegaram ao modelo vigente de gestão, gerenciamento e controle para o TRPP no estado da Bahia (Figura 1). Contudo, salienta-se que, ao apresentá-lo aos atores sociais públicos, estes mostravam dúvidas quanto às suas atribuições, mesmo executando-as em várias etapas do controle. Verificou-se que a sobrecarga de diversas funções, além das prescritas, e a necessidade de capacitação, que tem como um dos objetivos a compreensão melhor de seus papéis no campo do TRPP, reverberam no processo de não refletir sobre a abrangência de sua atuação na gestão e gerenciamento do TRPP como um todo.

A gestão, o gerenciamento e o controle do TRPP exercem suas atribuições com base em seu arcabouço legislativo, respeitando a Constituição Federal de 1988 (BRASIL, 1988), a Lei no 9.503/1997 (BRASIL, 1997) - que é o Código de Trânsito Brasileiro (CTB) -, as resoluções específicas do CONTRAN, as Resoluções ANTT no 3.886/2012 e 5.581/2017 (BRASIL, 2012; 2017) e suas atualizações, e as normas da Associação Brasileira de Normas Técnicas (NBRs-ABNT) associadas.

$\mathrm{Na}$ Bahia, acrescem-se ao arcabouço legislativo mencionado anteriormente a Resolução CEPRAM no 1.039/1994 (BAHIA, 1995), que dispõe sobre o controle de TRPP e do transporte dos resíduos destes produtos, observando as regulações citadas e outras relativas ao transporte de explosivos, de responsabilidade do Exército Brasileiro, a qual carece de revisão; a Resolução CEPRAM $\mathrm{n}^{\circ}$ 3.925/2009 (BAHIA, 2009), que trata do Programa Estadual de Gestão Ambiental Compartilhada; e a Resolução CEPRAM no 4.578/2017 e seus anexos (BAHIA, 2017), que dispõem sobre Gerenciamento de Riscos Acidentais para Substâncias Perigosas no Estado da Bahia, respeitando a Política Estadual de Meio Ambiente sob a Lei de no 12.377/2011 (BAHIA, 2011). As legislações específicas de cada instituição e transversal ao TRPP também fazem parte do campo de gestão e gerenciamento de risco em TRPP, ratificando a responsabilidade do controle estatal nesse tipo de atividade. Importante salientar que o TRPP segue os pressupostos da Política Ambiental do Ministério dos Transportes e está sujeito ao arcabouço legislativo ambiental do Ministério do Meio Ambiente. O conjunto robusto e complexo de legislação para o TRPP é parte imprescindível do controle desse tipo de transporte.

$\mathrm{Na}$ Figura 1, verifica-se que na Bahia o controle é acentuado nas etapas licenciamento, fiscalização e emergencial, mesmo havendo fragilidades nestas etapas. Isto mostra a necessidade de investir na prevenção, e tal ação perpassa a utilização de metodologias de avaliação de risco, elaboração de planos (por exemplo, viário, de contingência), levantamento 
do perfil dos produtos perigosos que transitam nas rodovias e estradas, dentre outros.

Figura 1: Fluxograma da gestão e gerenciamento de risco em TRPP na Bahia

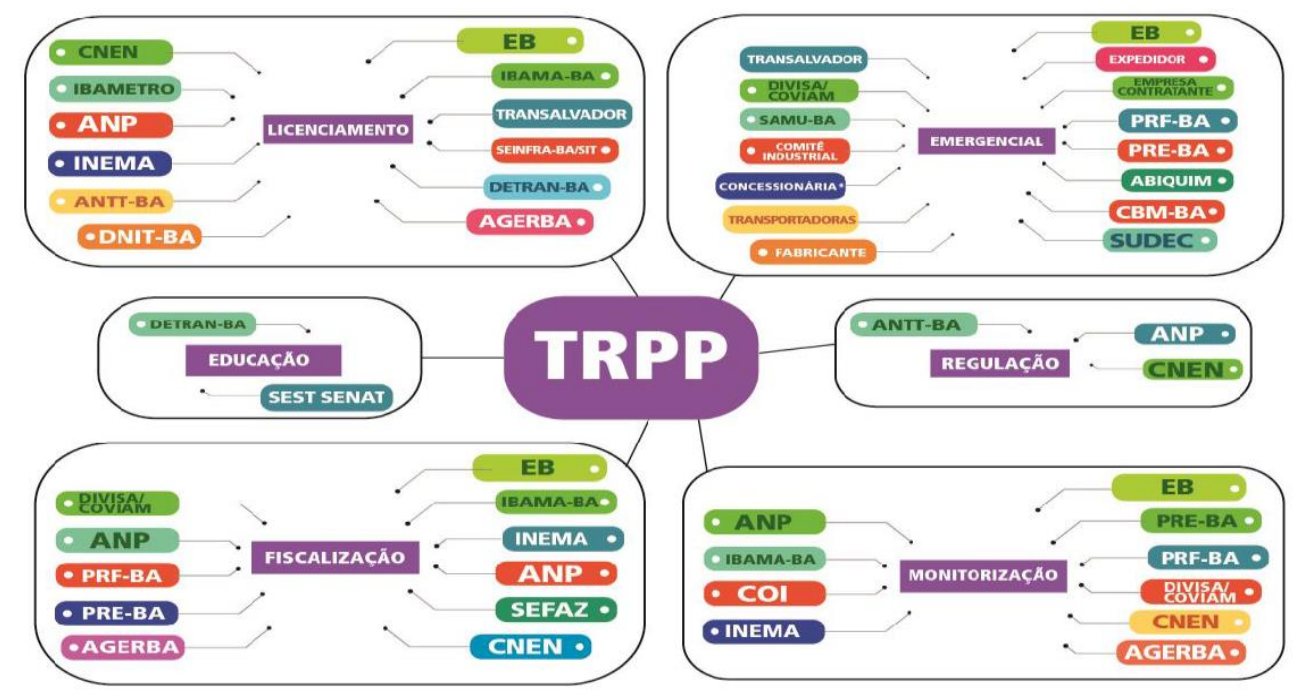

Fonte: Elaborada pelos autores.

Legenda: ANTT-BA (Agência Nacional de Transportes Terrestres na Bahia); SEINFRA-BA/SIT (Secretaria de Infraestrutura do Estado da Bahia/Superintendência de Infraestrutura de Transportes da Bahia); IBAMETRO (Instituto Baiano de Metrologia, Normalização e Qualidade); TRANSALVADOR (Superintendência de Trânsito de Salvador); DETRAN-BA (Departamento Estadual de Trânsito da Bahia); IBAMA-BA (Instituto Brasileiro do Meio Ambiente e Recursos Naturais Renováveis na Bahia); DNIT-BA (Departamento Nacional de Infraestrutura de Transportes na Bahia); ANP (Agência Nacional de Petróleo); PRE-BA (Polícia Rodoviária Estadual); EB (Exército Brasileiro); PRF-BA (Polícia Rodoviária Federal na Bahia); DIVISA/COVIAM (Diretoria de Vigilância Sanitária e Saúde Ambiental/Coordenação de Vigilância Ambiental); CBM-BA (Corpo de Bombeiros Militar da Bahia); DETRAN-BA (Departamento Estadual de Trânsito da Bahia); INEMA (Instituto do Meio Ambiente e Recursos Hídricos); CNEN (Comissão Nacional de Energia Nuclear); ABIQUIM (Associação Brasileira da Indústria Química); SAMU-BA (Serviço de Atendimento Móvel de Urgência da Bahia); COI (Centro de Operações e Inteligência da Bahia); SEST/SENAT (Serviço Social do Transporte/Serviço Nacional de Aprendizagem do Transporte); SUDEC (Superintendência Estadual de Proteção e Defesa Civil da Bahia); AGERBA (Agência Estadual de Regulação de Serviços Públicos de Energia, Transportes e Comunicações da Bahia); ANVISA (Agência Nacional de Vigilância Sanitária); CODEBA (Companhia das Docas do Estado da Bahia); CONAMA (Conselho Nacional do Meio Ambiente); CEPRAM (Conselho Estadual do Meio Ambiente).

\section{Vulnerabilidades e avanços no Controle de TRPP na Bahia}

As vulnerabilidades que se destacaram no controle de TRPP, especificamente para as instituições públicas, e que refletem diretamente em sua gestão e gerenciamento, são as seguintes:

a) fragilidades na intersetorialidade, o que culmina em dificuldades de troca de informações (dados) e de experiências e saberes específicos dos atores sociais envolvidos, e no fortalecimento de planejamento e ações integradas exigidas pelo princípio da precaução. A prática da intersetorialidade é ainda incipiente, mas observou-se que é fortalecida por gestores e técnicos mais atentos à questão;

b) baixos investimentos para capacitação técnica, tecnológica e recursos logísticos, o que dificulta o exercício dos órgãos públicos quanto às etapas do controle, pois são os mesmos para atuarem nestas além de terem outras atribuições simultaneamente. A etapa emergencial é a que mais apresenta atores sociais, o que mostra a necessidade de mapeamento e avaliação de riscos, fazendo com que recursos financeiros sejam direcionados para ações de prevenção e promoção da saúde e do ambiente, já que cada evento de trânsito com produtos perigosos custa $\mathrm{R} \$ 75.624,55$ (GOMES et al., 2016); 
c) a etapa de monitorização é crucial para o controle em TRPP e é a que apresenta maior vulnerabilidade, pois, devido aos escassos recursos financeiros para o campo de gerenciamento de TRPP, ela disputa com as outras etapas, além das vulnerabilidades de recursos técnicos e tecnológicos para dar conta de outras exigências do estado;

d) a participação no Plano Nacional de Prevenção, Preparação e Resposta Rápida a Emergências Ambientais com Produtos Químicos Perigosos (P2R2), coordenado pelo órgão ambiental do estado, o Instituto de Meio Ambiente e Recursos Hídricos (INEMA), exigido por lei, ainda é frágil e muitas instituições indicaram a dificuldade de diálogo dessa Instituição gestora com eles;

e) a mudança de status de Departamento para Superintendência ocorrida no órgão de Transportes do estado da Bahia, atualmente Superintendência de Infraestrutura de Transportes da Bahia (SIT), subordinada à Secretaria de Infraestrutura do Estado da Bahia (SEINFRA), que, refletindo a política econômica do País de redução de verbas para o campo de transportes, se traduziu na queda da qualidade de serviços viários, corroborando para o aumento de eventos de trânsito com produtos perigosos e a ausência de um plano específico para produtos perigosos. Com a supracitada mudança de status, há a diminuição de recursos financeiros e, simultaneamente, é notado o enxugamento do corpo técnico, por exemplo, inviabilizando ou dificultando as ações básicas exigidas para os objetivos preceituados em torno da segurança viária em geral e, neste caso, a segurança viária química;

f) dificuldade de disponibilidade de dados por alguns órgãos, devido à influência do pensamento e decisão estatal, e ausência de organização daqueles, traduzindo-se em mais uma vulnerabilidade político-institucional da governança de risco da Bahia por não ser ainda tratada como uma prioridade de governo;

g) ausência de estudos associados ao tempo de atendimento na etapa emergencial, o que resultará em ações de prevenção e promoção da saúde das populações e trabalhadores expostos a tal atividade;

h) ausência de informações sobre os eventos de trânsito específicos ao TRPP nos sites das instituições;

i) utilização de algumas legislações que necessitam de revisão; j) presença de conflitos de competências, o que faz acirrar a fragilidade na intersetorialidade;

k) necessidade de discussão sobre o conceito de risco (cada instituição possui uma percepção) e de transdisciplinaridade;

I) necessidade de capacitação de técnicos nas nove classes de risco dos produtos perigosos existentes;

m) o TRPP relacionado à classe de risco 7 (materiais e resíduos radioativos) merece uma atenção especial, pois, sendo os órgãos responsáveis por eles os de âmbito federal (IBAMA-BA e a CNEN, este último inexiste no estado), caso ocorra um evento adverso, o IBAMA-BA não possui estrutura para atuar sozinho, necessitando dos outros atores sociais. Tal situação implica que a esfera estadual atenda aos passivos ante a responsabilidade de segurança da população, o que contradiz o arcabouço legislativo pertinente. Além disto, não há ainda na Bahia um plano específico para este material que atenda às exigências de segurança à saúde e ao ambiente para as populações de influência direta e indireta.

Quanto às instituições privadas, segundo alguns documentos disponibilizados e/ou informações adquiridas em instituições públicas, as vulnerabilidades encontradas foram: a) revisão de planos de gerenciamento de carretas para produtos perigosos, segundo a atualização da legislação específica; e b) incrementar investimento em especialização dos condutores e na monitorização da segurança de seus veículos, para que possam circular em conformidade com a legislação específica de TRPP. As fragilidades identificadas indicam mais uma vulnerabilidade político-institucional no controle do setor privado quanto ao seu autogerenciamento de risco ambiental tecnológico em TRPP, bem como por parte do controle estatal.

\section{Um recorte da Segurança Química nas rodovias baianas: a Região Metropolitana de Salvador}

A rodovia BA-524 pode ser considerada uma das mais importantes do estado da Bahia, pois une o maior polo industrial do Hemisfério Sul ao Porto de Aratu. A rodovia atravessa três municípios da RMS de destaque industrial no estado (Camaçari, Simões Filho e Candeias) e é responsável praticamente pela circulação de mais de $20 \%$ do produto interno bruto do estado, incluídos os insumos e materiais perigosos que 
são distribuídos do Polo Industrial de Camaçari ao Porto de Aratu em Candeias ou vice-versa, e, também, para outros estados e o Mercosul, por outras rodovias que a interceptam.

A ANTT, órgão regulador do TRPP, por meio de três fiscalizações (blitzes) no ano de 2016, observou a existência de veículos que não podiam estar circulando nas rodovias por ferir princípios básicos, como a documentação específica e, dentre outros, ausência de aparelhos $e$ instrumentos que assegurem a segurança química, com sérios reflexos na segurança populacional, ambiental e viária.

No total, foram 128 notificações, mas neste artigo estão assinaladas apenas as consideradas mais importantes, conforme Quadro 1.

\section{Quadro 1: Inconformidades encontradas na RMS}

\begin{tabular}{|l|c|}
\hline \multicolumn{1}{|c|}{ INCONFORMIDADES } & PERCENTUAL (\%) \\
\hline Documentação veicular & 3 \\
\hline Documentação do(s) produto(s) transportado(s) & 11 \\
\hline Sinalização específica para o TRPP & 1 \\
\hline Incompatibilidade química & 21 \\
\hline $\begin{array}{l}\text { Equipamentos de situação de emergência } \\
\text { inadequados para uso }\end{array}$ & 6 \\
\hline $\begin{array}{l}\text { Ausência e embalagem sem identificação de } \\
\text { produtos }\end{array}$ & \\
\hline
\end{tabular}

Fonte: Elaborado pelos autores com base na ANTT (2016).

É importante salientar que a fiscalização é descontínua e aleatória, devido às vulnerabilidades político-institucionais, em consonância com o cenário político atual de redução de investimentos em setores essenciais para a população, como saúde, educação, transporte e segurança. Ocorrem, também, outras dificuldades, como estacionar muitos veículos no local onde é feita a fiscalização, pois os recursos humanos para este fim são insuficientes, ausência de estacionamento apropriado exigido por lei, além de produtos perigosos ficarem concentrados temporariamente em uma localidade que, por si só, já é um multicenário de risco.

Como já referido, os veículos que transportam estes produtos são predominantemente bitrens e rodotrens, então, o volume que transita na BA-524 é grande, o que, somado ao intervalo de tempo de um minuto que separa um caminhão de outro, acentua a insegurança já existente. Neste local, Gonçalves (2017) ressalta as vulnerabilidades socioambientais encontradas, o que intensifica 0 cenário de risco.

A inconformidade relacionada à sinalização específica para o TRPP na BA-524 contraria os princípios da segurança química adotada pelo Brasil por meio do uso do Sistema Globalmente Harmonizado de Classificação e Rotulagem de Produtos Químicos (Globally Harmonized System of Classification and Labeling of Chemicals), conhecido por Sistema GHS. Este é um ponto crítico no controle de risco ambiental tecnológico na Bahia, pois são fragilidades que refletirão na subnoticação de dados, em caso de ocorrência de eventos de trânsito. Por exemplo, se a simbologia não estiver em condições adequadas para identificação do produto e de sua classe de risco, dificultará uma atuação assertiva na etapa emergencial.

Há algo a ser discutido no estado da Bahia quando se considera a preocupação mundial com os eventos adversos com TRPP e suas consequências à saúde humana e ao ambiente, como destacado por Aguilera, Moyses e Moyses (2014), Ajaya Kumar et al. (2015) e WHO (2012, 2017), quanto aos princípios da segurança química. A atividade de TRPP e seus resíduos, segundo a Lei estadual $n^{\circ}$ 12.377/2011 (BAHIA, 2011), é enquadrada como de baixo ou médio potencial poluidor e, como tal, pode utilizar a Licença Ambiental por Adesão e Compromisso LAC, o que the confere ser concedida via on line, com informações prestadas pelo próprio empreendedor, sem fiscalização do estado e controle social. Tal situação fere a legislação ambiental de âmbito federal e reflete diretamente no quadro de vulnerabilidades políticoinstitucionais, socioambientais e populacional, ao facilitar ações que intensifiquem a insegurança química na Bahia. 
As inconformidades encontradas denotam a necessidade de atuação maior do Ministério do Trabalho e Emprego e do campo da Saúde do Trabalhador. As empresas transportadoras devem, segundo estabelece a legislação em TRPP, exercer a autofiscalização e automonitorização tanto das condições a que seus trabalhadores estão expostos, devido a uma pesada jornada de trabalho, como das condições viária, climáticas, sociais, dentre outras, e da segurança dos materiais perigosos a serem transportados.

Segundo Gonçalves (2017), algumas instituições públicas associadas à Segurança indicaram a necessidade de o setor privado relacionado ao TRPP ampliar mais o seu campo de ação na etapa emergencial, já que, conforme Araújo (2007), a preocupação deste último consiste em proteger os seus bens móveis e imóveis, lembrando também do Princípio de Poluidor-Pagador, que obriga o poluidor a arcar com os dispêndios dos passivos por ele causados ao meio ambiente. Bahia (2005) considera que os custos necessários à gestão do transporte de produtos perigosos são sustentados pela sociedade baiana, por meio dos impostos arrecadados, pagando por esta gestão até mesmo os que nem se utilizam dos produtos. Assim, Gonçalves (2017) sugere que a forma mais justa de onerar realmente os diretamente beneficiados pela gestão seria a cobrança de uma taxa a ser aplicada sobre o volume de produto perigoso e sobre a quilometragem de rodovia percorrida, devido à exposição do meio ambiente e do bem público ao perigo.

Contudo, os estudos desenvolvidos por Bahia (2005) e Gonçalves (2017) mostram que a melhor estrutura estadual em caso de ocorrência de eventos adversos concentra-se na Região Metropolitana da Salvador. O Polo Industrial de Camaçari, localizado neste território, possui e oferece, quando solicitado pela gestão pública, recursos humanos e tecnológicos que, unidos ao do estado, atuam em eventos adversos com TRPP e outros de cunho tecnológico, mas não os de grandes proporções. Gonçalves (2017) indica também a necessidade de investimentos em estudos toxicológicos e ecotoxicológicos dos materiais que circulam nas rodovias baianas, mesmo já havendo pesquisas neste campo para aqueles que possuem a ficha de informações de segurança de produtos químicos (FISPQ), um dos documentos obrigatórios para o transporte destes materiais. Muitas vezes, as FISPQs existentes não estão atualizadas e muitas informações dos materiais perigosos ali descritos não estão completas, o que potencializa a insegurança química nestas rodovias. Além disto, sugere a inserção de estudos epidemiológicos envolvendo os eventos adversos de trânsito com aquelas substâncias.

As reuniões de P2R2 responsáveis pela discussão e ação de segurança química na Bahia não ocorrem desde 2016, segundo informação da DIVISA/COVIAM (2018). Observa-se que medidas de prevenção que poderiam ser tomadas pelos agentes de gerenciamento de risco ambiental tecnológico, também associadas ao TRPP, são dispostas à margem, denotando a presença de mais uma vulnerabilidade políticoinstitucional.

A avaliação nacional sobre a infraestrutura viária da Bahia considera-a inadequada em $63,4 \%$ (total de rodovias classificadas como péssimas, ruins e regulares) e boa em $36,6 \%$ (rodovias boas e ótimas) para a circulação de bens, mesmo com implementação de melhorias. Oliveira, Freitas e Silva (2016, p. 259) acreditam que a "infraestrutura viária baiana aparenta ser precária, seletiva, limitada, desintegrada e ultrapassada", o que concorre para um TRPP inseguro, devido à política nacional de redução de investimentos em infraestrutura rodoviária e pela demanda de mercados exigindo uma grande circulação destes produtos.

Segundo Ruppenthal (2013), diariamente, produtos perigosos são produzidos pelos mercados, uma média de 1.000 a 2.000 substâncias novas, necessitando de estudos de suas propriedades intrínsecas. A RMS e a capital do estado da Bahia não apresentam planos viários e, consequentemente, planos de contingência para os materiais perigosos movimentados em suas rodovias (BAHIA, 2005; CNT, 2016; SIT, 2016, 2017b).

\section{Avanços em TRPP}

Alguns avanços encontrados por Gonçalves (2017), quanto ao controle por parte das instituições públicas, e também privadas, foram os seguintes:

\section{1 - Campo da Saúde}

A Coordenação de Vigilância Ambiental Estadual (COVIAM), no âmbito do VIGIDESASTRES, investe em constante 
atualização de seu corpo técnico, a exemplo do curso internacional em Avaliação de Impactos à Saúde (AIS), junto à Fundação Osvaldo Cruz (FIOCRUZ) da Bahia, sendo um dos pioneiros no Brasil a aplicar esta metodologia específica de avaliação de riscos no campo da Saúde, em uma localidade da RMS com histórico de riscos e desastres tecnológicos no estado. Foram realizadas oficinas e elaborados planos multirriscos em saúde, dentre estes, envolvendo o TRPP, abarcando ainda $15 \%$ dos municípios expostos à questão; porém, não atingiram o Município de Caetité, que apresenta a única mineração de urânio em atividade no Brasil e da América Latina, cujo trajeto do transporte ocorre originado no Sudoeste baiano, tendo como ponto final o Porto de Salvador, na capital do estado. O campo da saúde é o que mais provoca o diálogo entre os atores sociais envolvidos na temática.

O Serviço de Atendimento Móvel de Urgência da Bahia (SAMU-BA), instituição que atua na etapa emergencial, possui um dos especialistas da América Latina com formação internacional em emergências químicas e em capacitação de equipes para lidar com desastres tecnológicos, formando e capacitando a equipe do Órgão para eventos adversos com TRPP. A Instituição participa e promove ações intersetoriais para 0 fortalecimento das políticas públicas de prevenção e promoção à saúde associadas ao tema. Contudo, ainda é insuficiente para as demandas da RMS e do estado da Bahia, de uma maneira geral.

\section{2 - Campo dos Transportes}

Elabora-se um banco de dados das fiscalizações feitas pela Agência Nacional de Transportes Terrestres (ANTT) desde 2016, com a disposição de fortalecer a intersetorialidade, como a participação em blitz, realização de pesquisa científica junto à Universidade Federal da Bahia, no Programa de Pós-Graduação em Saúde, Ambiente e Trabalho (PPgSAT), e trabalho em conjunto com o setor de Segurança, Trânsito e Transporte, como a Polícia Rodoviária Estadual da Bahia. Quanto à Secretaria de Infraestrutura do Estado da Bahia/Superintendência de Infraestrutura de Transportes da Bahia (SEINFRA-BA/SIT), verificou-se: a) implementação do PREMAR I e II, em que o primeiro se ocupou com a recuperação e manutenção de algumas rodovias, e o segundo que se diferencia ao inserir o componente social, elemento imprescindível no campo dos transportes, contudo, não sinaliza especificamente para as populações lindeiras expostas ao TRPP; b) elaboração de um banco de dados integrado com algumas instituições, mas com o objetivo de segurança de trânsito em geral; c) implantação de novas tecnologias para monitorização do trânsito em tempo real, abrangendo inicialmente determinadas localidades; e d) uma política de fortalecimento da intersetorialidade.

\section{3 - Campo de Segurança e Trânsito Esfera} federal: A Polícia Rodoviária Federal da Bahia (PRF-BA) possui o mais robusto banco de dados de eventos de trânsito com produtos perigosos no estado, com constante aperfeiçoamento do boletim de ocorrências destes, e apresenta crescimento em ações intersetoriais.

\section{Esfera estadual}

a) A Polícia Rodoviária Estadual (PRE-BA) apresenta avanços, como o fortalecimento na intersetorialidade, sendo um referencial em diálogo com todas as instituições envolvidas, sejam estas públicas ou privadas; capacitação trimestral de seu quadro técnico para minimizar as questões de subnotificação de dados com eventos de trânsito em produtos perigosos; inclusão de uma disciplina sobre o TRPP na formação acadêmica militar; e banco de dados de eventos com TRPP integrado com a SIT.

b) O Corpo de Bombeiros Militar da Bahia (CBMBA) é a Instituição que está investindo em capacitação internacional de seu corpo técnico e na elaboração de um plano de emergências químicas, incluídas ações associadas ao TRPP.

c) O Departamento Estadual de Trânsito da Bahia (DETRAN-BA) oferece um curso gratuito específico para o TRPP, o MOPP (Movimentação de Produtos Perigosos) com carga horária de 40 horas, estando a Instituição em diálogo com diversos atores sociais para a elaboração de um banco de dados integrados e que abranja o TRPP.

\section{4 - Campo Ambiental}

O IBAMA-BA apresenta equipe que capacita técnicos da Instituição em alguns estados do País e possui recursos humanos e logísticos para atuar em emergências químicas. 


\section{5 - Instituições Públicas denominadas} Estruturantes

Dentre estas, menciona-se, por exemplo, o IBAMETRO, que apresentou como avanços a ampliação dos pátios de avaliação dos veículos e a terceirização de serviços para efetuar liberação de autorizações para o transporte de cargas em geral. Devem ser consideradas as fragilidades já existentes no controle da atividade, aliadas à fiscalização e monitorização da qualidade desses serviços ante as vulnerabilidades do corpo técnico para exercer as atividades já préestabelecidas.

\section{6 - Instituições Privadas}

Apresentam avanços, como a implementação de planos envolvidos com segurança e saúde da atividade de TRPP e utilização de tecnologias e estruturas emergenciais mais avançadas em relação ao Estado.

\section{CONSIDERAÇÕES FINAIS}

O transporte rodoviário de produtos perigosos na Bahia apresenta riscos e vulnerabilidades enfrentadas desde os primeiros estudos sobre a temática, ocorridos no final da década de 80 . Os avanços são ainda incipientes, levando em consideração o crescimento constante da evolução tecnológica oriunda das demandas da industrialização e dos acordos internacionais para compatibilizar os conclames do mercado, os princípios da sustentabilidade e da governança de risco em um mundo globalizado. A Bahia é um dos expoentes de produção química e petroquímica brasileira e, assim, deve cumprir as exigências do arcabouço legislativo específico e dos atores sociais envolvidos, bem como o Plano Nacional de Prevenção, Preparação e Resposta Rápida a Emergências Ambientais com Produtos Químicos Perigosos (P2R2), assegurando a minimização dos riscos e vulnerabilidades do TRPP em suas rodovias.

O cenário encontrado, quanto à ausência de mapeamento de riscos, ao não uso de metodologias de avaliação de riscos tecnológicos e à subnotificação de dados de eventos adversos em TRPP, principia o delineamento do quadro de vulnerabilidades político-institucionais da Bahia, na área de planejamento em gestão integrada de risco ambiental tecnológico, sendo essas vulnerabilidades um ponto crucial do problema. A adoção do conceito de risco objetivo associado à temática fortalece a ideia de que as evidências científicas são as mais adequadas para a perspectiva de percepção de risco ambiental tecnológico, favorecendo, assim, as ações neoliberais no campo do gerenciamento desse risco em detrimento da participação e controle social.

A inexistência de mapeamento de riscos e de uso de metodologias de avaliação de riscos em TRPP contraria as políticas em saúde, meio ambiente e de transporte em TRPP apregoadas pelos Objetivos de Desenvolvimento do Milênio (que teve vigência até 2015), Agenda 2030 para o Desenvolvimento Sustentável e a Década de Ação pela Segurança no Trânsito.

O campo da Saúde apresentou maiores avanços no gerenciamento do risco ambiental tecnológico em TRPP, devido a investimentos contínuos em capacitação e fortalecimento da intersetorialidade com os atores sociais envolvidos e com a sociedade. O campo do trânsito e da segurança destaca-se pelo intersetorialidade e desenvolvimento de bancos de dados específicos e suas atualizações. O campo ambiental precisa, inicialmente, de ações de intersetorialidade.

As populações de vulnerabilidades socioeconômicas e ambientais e os trabalhadores que lidam diretamente com materiais perigosos são os que mais sofrem com os passivos, sejam estes os riscos potenciais ou os advindos com os eventos adversos de trânsito com TRPP. Há, assim, necessidade de investimentos em pesquisas na temática (escassas no estado da Bahia), de uso de instrumentos como mapeamento, avaliação e percepção de riscos dos atores sociais envolvidos e de fortalecimento da intersetorialidade, os quais podem se constituir em algumas saídas para as fragilidades encontradas e refletir na melhoria do cenário do TRPP ainda vigente. Tal cenário é repleto de incertezas tecnológicas e metodológicas e de insegurança viária que intensificam a insegurança química crescente, reverberando diretamente na vulnerabilidade ambiental. Exige-se um planejamento ambiental integrado, sendo o ambiente compreendido em seu caráter multidimensional como estabelece o conceito atual de gestão ambiental.

O cumprimento efetivo da legislação específica de TRPP no estado da Bahia e da Lei estadual no 12.618/2012 (Lei de Acesso às Informações) (BAHIA, 2012) permitirá o 
favorecimento de delineamento do cenário mais preciso do TRPP, bem como contribuirá para a elaboração de estudos e políticas públicas, o que refletirá diretamente nas atividades de gestão e gerenciamento de risco ambiental tecnológico desse tipo de transporte.

A questão é de ordem estrutural e que, portanto, precisa ser vista pelo Estado como uma de suas prioridades, bem como atentar para as soluções de um modelo econômico cujo risco tecnológico complexo e desigual é naturalizado e intensifica a injustiça ambiental, constituindo-se em um problema de governança de risco, em que é solicitado um modelo sustentável, de equidade em saúde e ambiente.

\section{Limitações}

O trabalho apresenta algumas limitações dado ao tempo exíguo para entrevistar algumas instituições públicas e privadas associadas ao tema, bem como à indisponibilidade de dados de algumas instituições visitadas e contatadas. No campo Educação, também por limitação temporal, não puderam ser avaliados os currículos de cursos oferecidos por universidades e cursos técnicos para verificação de como o tema é tratado, assim como as ações educativas realizadas por instituições envolvidas na temática, sendo que a questão se restringiu à formação dos condutores, o mesmo acontecendo no campo da Comunicação, limitações estas que ficam para serem superadas em trabalhos futuros.

\section{REFERÊNCIAS}

AGUILERA, S. L. V. U.; MOYSES, S. T.; MOYSES, S. J. Intervenções de segurança viária e seus efeitos nas lesões causadas pelo trânsito: uma revisão sistemática. Rev. Panam Salud Publica, Washington, v. 36, n. 4, p. 257-265, 2014.

AJAYA KUMAR, K.; TÂMIL SELVAN, R.; NEHAL A, S.; ASHUTOSH, G. Scope for developing accident causation model of road transportation of hazardous materials. International Advanced Research Journal in Science, v. 2, p. 57-63, 2015. Disponível em: < http://www.iarjset.com/upload/2015/october-

15/IARJSET\%2012.pdf>. Acesso em: 17 set. 2017.

ANTT. Agência Nacional de Transportes Terrestres. Resumo de Fiscalização - Produtos Perigosos. Salvador: ANTT/URBA, 2016.

ARAÚJO, G. M. Regulamentação de transporte terrestre de produtos perigosos comentada. 2. ed.
Rio de Janeiro: Editora Gerenciamento Verde e Livraria Virtual, 2007. 964 p.

Sistemas de gestão de riscos: estudos de análise de riscos "Offshore e Onshore". 2. ed. Rio de Janeiro: Editora Gerenciamento Verde e Livraria Virtual, 2013.

BAHIA. Plano de Contingência para acidentes com cargas perigosas em rodovias do Estado da Bahia. Salvador: DERBA, 2005.

Conselho Estadual de Meio Ambiente (CEPRAM). Resolução $n^{\circ} 1.039$, de 06 de dezembro de 1994. Aprova a Norma Administrativa NA-001/94, que dispõe sobre o Controle do Transporte Rodoviário de Produtos e Resíduos Perigosos no Estado da Bahia. Diário Oficial do Estado da Bahia, Poder Executivo, Bahia, edição de 31 mar. 1995.

Conselho Estadual de Meio Ambiente (CEPRAM). Lei no 3.925, de 30 de janeiro de 2009, que dispõe sobre o Programa Estadual de Gestão Ambiental Compartilhada com fins ao fortalecimento da gestão ambiental, mediante normas de cooperação entre os Sistemas Estadual e Municipal de Meio Ambiente, define as atividades de impacto ambiental local para fins do exercício da competência do licenciamento ambiental municipal, e dá outras providências. Diário Oficial do Estado da Bahia, Poder Executivo, Bahia, edição de 04 mar. 2009.

Conselho Estadual de Meio Ambiente (CEPRAM). Lei no 12.377, de 28 de dezembro de 2011, que altera a Lei $\mathrm{n}$ - 10.431 , de 20 de dezembro de 2006, que dispõe sobre a Política Estadual de Meio Ambiente e de Proteção à Biodiversidade, a Lei no 11.612, de 08 de outubro de 2009, que dispõe sobre a Política Estadual de Recursos Hídricos e a Lei no 11.051, de 06 de junho de 2008, que Reestrutura 0 Grupo Ocupacional Fiscalização e Regulação. Diário Oficial do Estado da Bahia, Poder Executivo, Bahia, edição de 29 dez. 2011.

. Lei $\mathrm{n}^{\circ} 12.618$, de 28 de dezembro de 2012 , que Regula o acesso a informações no âmbito do Estado da Bahia, conforme prevê o art. 45 da Lei Federal no 12.527, de 18 de novembro de 2011, e dá outras providências. Diário Oficial do Estado da Bahia, Poder Executivo, Bahia, edição de 28 de dez. de 2012.

Conselho Estadual de Meio Ambiente (CEPRAM). Resolução CEPRAM no 4.578, de 29 de setembro de 2017, que aprova a Norma Técnica NT 01/2017 e seus Anexos, que dispõe sobre o Gerenciamento de Riscos Acidentais para Substâncias Perigosas no Estado da Bahia e revoga a Resolução CEPRAM de no 3.965, de 30 de junho de 2009 e demais disposições em contrário. Diário Oficial do 
Estado da Bahia, Poder Executivo, Bahia, edição de 11 out. 2017.

BRASIL. Constituição da República Federativa do Brasil: texto constitucional promulgado em 05 de outubro de 1988, com as alterações determinadas pelas Emendas Constitucionais de Revisão nos 1 a 6/94, pelas Emendas Constitucionais nos 1/92 a 91/2016 e pelo Decreto Legislativo no 186/2008. Brasília: Senado Federal, Coordenação de Edições Técnicas, 2016. 496 p. Diário Oficial [da] República Federativa do Brasil, Poder Executivo, Brasília, DF, 05 out. 1988. Seção 1, p. 1. (Publicação Original).

Lei no 9.503, de 23 de setembro de 1997. Institui o Código de Trânsito Brasileiro. Diário Oficial [da] República Federativa do Brasil, Brasília, DF, 24 set. 1997. Seção 1, p. 21.201.

Decreto no 5.098, de 03 de junho de 2004. Dispõe sobre a criação do Plano Nacional de Prevenção, que dispõe sobre a criação do plano nacional de prevenção, preparação e resposta rápida a emergências ambientais com produtos químicos perigosos - P2R2, e dá outras providências. Diário Oficial [da] República Federativa do Brasil, Poder Executivo, Brasília, DF, 04 jun. 2004. Seção 1, p. 2.

Ministério dos Transportes, Portos e Aviação Civil. Agência Nacional de Transportes Terrestres. Resolução no 3.886, de 06 de setembro de 2012, que altera a Resolução ANTT no 5.232 de 2016, que aprova as Instruções Complementares ao Regulamento Terrestre do Transporte de Produtos Perigosos, e seu anexo. Diário Oficial [da] República Federativa do Brasil, Poder Executivo, Brasília, DF, 12 de set. 2012. Seção 1, p. 50.

Ministério dos Transportes, Portos e Aviação Civil. Agência Nacional de Transportes Terrestres. Resolução no 5581, de 22 de novembro de 2017, que altera a Resolução ANTT $n \cong$ 5.232, de 2016, que aprova as Instruções Complementares ao Regulamento Terrestre do Transporte de Produtos Perigosos, e seu anexo. Oficial [da] República Federativa do Brasil, Poder Executivo, Brasília, DF, 23 de nov. 2017. Seção 1, p. 88.

BELTRAMI, A. C.; FREITAS, C. M.; MACHADO, J. H. M. Acidentes com produtos perigosos no Brasil, no período 2006-2009: análise dos dados dos sistemas de informações como subsídio às ações de vigilância em saúde ambiental. Epidemiol. Serv. Saúde, Brasília, v. 21, n. 3, p. 439-448, 2012.

CNT. Confederação Nacional de Transporte. Pesquisa CNT de rodovias 2016. 2016. Disponível em:

$<$ Http://pesquisarodoviascms.cnt.org.br/relatorio\%20ger al/pesquisa\%20cnt\%20(2016)\%20- \%20LOW.pdf>. Acesso em: 06 ago. 2018.
DECLARAÇÃO DO RIO DE JANEIRO. Estud. Av. São Paulo, v. 6, n. 15, p. 153-159, ago. 1992.

DETRAN-BA. Departamento de Trânsito da Bahia. Relatório da evolução da frota baiana de veículos do período de 2000 a 2017. Salvador, 2017. 3p.

DETRANS. In: CONGRESSO BRASILEIRO DA ASSOCIAÇÃO NACIONAL DOS DETRANS:Tecnologia na Área de Trânsito e Cidades do Futuro, 2., 2017, Salvador. Anais... Salvador: Associação Nacional dos Detrans, 2017.

FREITAS, C. M. de. Avaliação de riscos como ferramenta para a vigilância ambiental em Saúde. Inf. Epidemiol. Sus, Brasília, v. 11, n. 4, p. 227-239, 2002.

; SILVA, E. L.; SILVA, I. V. M; MAZOTO, M. L.; SILVA, M. A; ALPINO, T. M. A.; MELLO, T. C. C.; ROCHA, V. Relatório "Fortalecimento das capacidades de prontidão e resposta frente a situações de emergência de interesse de saúde pública: Bahia e Salvador. Rio de Janeiro: Centro de Estudos e Pesquisas em Emergências e Desastres em Saúde (CEPEDES/FIOCRUZ), 2013. 32p.

GOMES, M. A. C.; MOREIRA, M.; BATISTOTE, J. R.; RESTANHO, N.; GOIA, F.; NOBREGA, I.; CARLOS, R. C. Produtos perigosos: uma visão prática da legislação. Goiânia: Editora Kelps, 2016. 350 p.

GONÇALVES, L. M. S. Avaliação de riscos potenciais associados ao transporte rodoviário de produtos perigosos na Região Metropolitana de Salvador-BA. 2017. 301f. Dissertação (Mestrado em Saúde, Ambiente e Trabalho) - Faculdade de Medicina da Bahia, Universidade Federal da Bahia, Salvador, 2017.

; AGUIAR; T. S.; DA SILVA, B. P.; D'AREDE, C. O. Acidentes com transporte rodoviário de produtos perigosos na Bahia: desafios para a década de ação pela segurança no trânsito. In: CONGRESSO BRASILEIRO DA ASSOCIAÇÃO NACIONAL DOS DETRANS: Tecnologia na Área de Trânsito e Cidades do Futuro, 2., 2017, Salvador. Anais... Salvador: Associação Nacional dos Detrans, 2017. p.16.

GONÇALVES, L. S. G.; D'AREDE, C. O.; MORAES, L. R. S. Acidentes com transporte rodoviário de produtos perigosos na Bahia: um olhar ampliado. In: FOLQUITTO, D. G. (Org.). Alicerces da saúde pública no Brasil.1. ed. Ponta Grossa Paraná: Atena Editora, 2018. v. 1, p. 211-229. E-book. ISBN 978-8585107-18-5. Disponível em:

$<$ http://http://www.atenaeditora.com.br/wpcontent/uploads/2018/08/E-book-Alicerces-daSa\%C3\%BAde-1.pdf>. Acesso em: 12 jun. 2018.

FREITAS, C. M. de et al. Relatório Fortalecimento das capacidades de prontidão e resposta frente a 
situações de emergência de interesse de saúde pública: Bahia e Salvador. Rio de Janeiro: Centro de Estudos e Pesquisas em Emergências e Desastres em Saúde (CEPEDES/FIOCRUZ), 2013. 32p.

IBAMA. Instituto Brasileiro do Meio Ambiente e dos Recursos Naturais Renováveis. Acidentes Ambientais 2014. Relatório. Distrito Federal, Brasília, 2015.

INEMA. INSTITUTO DE MEIO AMBIENTE E RECURSOS HÍDRICOS - Dados de 207 acidentes ambientais no período de 2010 a 2014. Banco de dados CERBERUS, Salvador, 2015.

MOREIRA, F. (Org.). Saúde \& trânsito. Rio de Janeiro: Arquimedes, 2015. 202 p.

NAVARRO, M. V. T. Risco, radiognóstico e vigilância sanitária. Salvador: EDUFBA, 2009. 166 p.

OLIVEIRA, H. C.; FREITAS, U. R. P; SILVA, L. P. Panorama da infraestrutura de transporte baiana: 2007 a 2014. Rev. Análise \& Dados (SEI), v. 26, p. 257 276, 2016.

PRF-BA. POLÍCIA RODOVIÁRIA FEDERAL (Bahia). Análise de acidentes com produtos perigosos nas rodovias baianas no período de 2010 a 2014. Salvador, Bahia, 2015.

PORTO, M. F.; FINAMORE, R. Riscos, saúde e justiça ambiental: o protagonismo das populações atingidas na produção de conhecimento. Ciênc. Saúde Coletiva, Rio de Janeiro, v. 17, n. 6, p. 1493-1501, 2012.

RUPPENTHAL, J. E. Toxicologia. Santa Maria: Universidade Federal de Santa Maria, Colégio Técnico Industrial de Santa Maria; Rede e-tec, Brasil, 2013.

SÁNCHEZ, L. E. Avaliação de impacto ambiental: conceitos e métodos. 2 ed. São Paulo: Oficina de Textos, 2008.

WHO. World Health Organization. Report WHO Checa Safety-Active Report. Genéve, 2012. Disponível em: $<$ htpp://www.who.int/pcs/about

ipcs/activityreport2012.pdf>. Acesso em: 20 ago. 2018.

Document The role of the health sector in the Strategic Approach to International Chemicals Management towards the 2020 goal and beyond: Seventieth World Health Assembly. 2016.

Chemical Safety-Active Report. Genéve, $2017 . \quad$ Disponível em: <http://apps.who.int/gb/ebwha/pdf_files/WHA70/A70_36 -en.pdf. >. Acesso em: 16 jun. 2018.

\section{Entrevistas:}

AGERBA. Agência Estadual de Regulação de Serviços Públicos de Energia. Entrevista realizada em 03.03.2017, Salvador-BA, 2017a. Entrevista concedida a L. M. da Silva Gonçalves.

ANTT-BA. Agência Nacional de Transportes Terrestres (Bahia). Entrevista realizada em 10.01.2017, SalvadorBA, 2017a. Entrevista concedida a L. M. da Silva Gonçalves.

CBM-BA. Corpo dos Bombeiros Militar da Bahia. Entrevista realizada em 06.04.2017, Salvador-BA, 2017. Entrevista concedida a L. M. da Silva Gonçalves.

COI. Centro de Operações e Inteligência da Bahia. Entrevista realizada em 31.03.2017, Salvador-BA, 2017. Entrevista concedida a L. M. da Silva Gonçalves.

DETRAN-BA. Departamento de Trânsito da Bahia. Entrevista realizada em 20.03.2017, Salvador- BA, 2017b. Entrevista concedida a L. M. da Silva Gonçalves.

DIS. Diretoria de Informação em Saúde. Entrevista realizada em 20.03.2017, Salvador-BA, 2017. Entrevista concedida a L. M. da Silva Gonçalves.

DIVISA/COVIAM. Diretoria de Vigilância Sanitária e Saúde Ambiental (Coordenação de Vigilância Ambiental). Secretaria de Saúde do Estado da Bahia. Entrevista realizada em 16.02.2017, Salvador-BA. Entrevista concedida a L. M. da Silva Gonçalves.

Diretoria de Vigilância Sanitária e Saúde Ambiental (Coordenação de Vigilância Ambiental). Secretaria de Saúde do Estado da Bahia. Entrevista realizada em 20.07.2018, Salvador-BA. Entrevista concedida a L. M. da Silva Gonçalves.

DNIT-BA. Departamento Nacional de Infraestrutura de Transportes (Bahia). Entrevista realizada em 16.02.2017, Salvador-BA. Entrevista concedida a L. M. da Silva Gonçalves.

IBAMA-BA. Instituto brasileiro do Meio Ambiente e dos Recursos Naturais Renováveis (Bahia). Acidentes Ambientais. Entrevista realizada em 20.02.2017, Salvador-BA. Entrevista concedida a L. M. da Silva Gonçalves.

IBAMETRO. Instituto Baiano de Metrologia e Qualidade. Entrevista realizada em 28.03.2017, Salvador-BA. Entrevista concedida a L. M. da Silva Gonçalves. 
PRE-BA Polícia Rodoviária Estadual da Bahia. Entrevista realizada em 08.03.2017, Salvador- BA, 2017. Entrevista concedida a L. M. da Silva Gonçalves.

PRF-BA. Polícia Rodoviária Federal (Bahia). Entrevista realizada em 10.01.2017 em Porto Seco Pirajá, Simões Filho, Bahia. Entrevista concedida a L. M. da Silva Gonçalves.

QUILOMBO DE PITANGA DE PALMARES. Entrevista realizada em 23.03.2017, Simões Filho-BA. Entrevista concedida a L. M. da Silva Gonçalves.

SASDERBA. Associação Assistencial dos Servidores do Derba. Entrevista realizada 11.02.2017 em Porto Seco Pirajá, Simões Filho, Bahia. Entrevista concedida a L M da Silva Gonçalves.

SINDICARGAS. Sindicato dos Trabalhadores em Transportes Rodoviários de Cargas do Estado da Bahia. Entrevista realizada em 29.03.2017, Camaçari, Bahia. Entrevista concedida a L. M. da Silva Gonçalves.
SIT. Superintendência de infraestrutura de Transportes da Bahia. Entrevista em 01.02.2017, Salvador, Bahia. 2017a. Entrevista (Estrutura e funcionamento da SITDepartamento de Operações de Trânsito) concedida a L. M. da Silva Gonçalves.

SIT. Superintendência de infraestrutura de Transportes da Bahia. Entrevista em 13.02.2017, Salvador, Bahia. 2017b. Entrevista concedida a L. M. da Silva Gonçalves.

SUDEC. Superintendência de Defesa Civil da Bahia. Entrevista realizada em 29.12.2016, Salvador-BA. Entrevista concedida a L. M. da Silva Gonçalves.

SAMU-BA. Serviço de Atendimento Móvel de Urgência. Entrevista realizada em 29.12.2016, Salvador-BA. Entrevista concedida a L. M. da Silva Gonçalves.

TRANSALVADOR. Superintendência de Trânsito de Salvador. Entrevista concedida por telefone em 06.04.2017. Entrevista concedida a L. M. da Silva Gonçalves. 